\title{
A pedagogical framework for embedding C\&IT into the curriculum
}

\author{
Grainne Conole and Martin Oliver \\ Learning and Teaching Innovation and Development Unit, University of North London. \\ Email: g.conole@unl.ac.uk
}

This paper proposes a methodology for effectively embedding communication and information technologies (C\&IT) into the curriculum. This builds on existing frameworks for designing courses involving C\&IT. A hypothetical illustration of this process is provided, and issues relating to the adoption and application of the methodology are identified.

\section{Introduction}

A wide variety of communication and information technologies (C\&IT) is now available, offering education a broad range of potential benefits, be they educational (Mapp, 1994; Lewis and Merton, 1996; HEFCE, 1997a), economic (HEFCE, 1997a), or in terms of competitiveness with other universities in an increasingly global market (Maier et al, 1997). The uptake and use of these resources is patchy at best (Laurillard et al, 1993; Lewis and Merton, 1996). This mismatch between potential and use has been seen as increasingly important, and incentives and recommendations are leading to an increasing use of C\&IT, as illustrated by the recommendations of the recent Dearing report (Dearing $e t$ al, 1997) and the priorities of the TLT programme (HEFCE, 1997b). Concerns have been voiced, however, that the push towards a wider embedding of C\&IT in education may ignore issues of the appropriate uses of these resources. What is needed is a convincing and practical pedagogically-driven (as opposed to technology-driven) methodology for integrating C\&IT into courses.

This paper seeks to address this issue by proposing a pedagogically sound methodology for integrating C\&IT into courses. It reviews recent frameworks for course design, discusses the findings of a pilot study that seeks to inform this process, and presents a methodology which incorporates the following:

- the definition of a learning scenario, in terms of the stages of learning;

- the mapping of learning scenarios to the types of media best suited to supporting them;

4 
- the specification of related resource requirements.

The resultant methodology forms a five-stage process whose emphasis is on providing practical support for practitioners who aim to embed C\&IT into their courses. This support includes tools for weighing the educational and economic advantages of C\&IT , guidelines for embedding materials in an integrated fashion, and a means of specifying the supporting resources the enhanced course will require.

The methodology aims to be neutral with respect to educational philosophies, attempting to avoid commitment to constructivism (e.g. Grabinger et al, 1997), Fordism (e.g. McAleese et al, 1997), and so on, leaving the choice of position to the practitioners who use the model. It does, however, draw on Laurillard's conversational framework (1993) as a model for educational interactions.

\section{Existing frameworks for embedding C\&IT}

A variety of frameworks already exist which can be used to design courses incorporating C\&IT . In this section, three examples of these will be briefly reviewed. These represent three distinct approaches to the process, and so provide a useful overview of the range of issues associated with embedding C\&IT . (A more detailed discussion of these approaches, and their relationship with the framework proposed in this paper, can be found in Conole and Oliver, 1997.) Finally, the complementary elements of these are drawn together in order to create a new framework.

\section{The Open Learning Foundation framework}

Work by the Open Learning Foundation has led to the definition of a framework for implementing C\&IT (Mapp, 1994) which consists of four interrelated elements: institutional infrastructure, the learning environment, human and institutional relationships, and the learning materials. It should be noted that the framework is intended to form the focus of discussion of C\&IT-related issues, and not a procedure by which this is achieved.

\section{A methodology for integrated learning environment design}

A more structured procedure for designing integrated learning environments, which shares many themes with the Open Learning Foundation framework, has been proposed by Lewis and Merton (1996). This takes students' needs and learning styles as the starting point of the process of embedding C\&IT into the curriculum, expanding on this using the following steps:

- identification of students' learning needs;

- identification of student access needs skill requirements;

- consideration of the organization and presentation of the curriculum, including:

- learning outcomes,

- learning methods,

- sequence of methods and media,

- assessment methods,

- learning hours,

- access. 
This methodology adopts a much clearer focus on individual courses than that of the Open Learning Foundation, through its emphasis on learning. The specification of objectives and methods is not intended to be prescriptive. The methodology centres around a series of questions, aimed at practitioners, which are intended to promote reflection on key issues of C\&IT use in relation to student learning. These questions include:

- What are the students trying to achieve?

- What are the best ways of achieving these outcomes?

- What different routes are available to students pursuing these outcomes?

The application of learning technology to curriculum design

A third approach to integrating C\&IT is provided by Harrison (1994), whose framework concentrates on curriculum design and delivery. For this reason, practitioners become central to the process, providing expertise on course-related issues such as student needs and assessment methods. Harrison proposes that the following steps form the planning process for the new style of flexible learning:

- clarify the course's aims and learning outcomes;

- consider whether to write, buy or adopt supporting materials;

- consider whether course content can be based on existing materials, or needs to be developed for this particular course;

- establish a course overview;

- decide on the academic level of the course (Is it introductory? Are any other courses prerequisites?);

- select appropriate assessment models (Multiple-choice or open assignments? Student, tutor or computer marked?).

An important factor external to this process is the role of formative evaluations of the revised course, creating an ongoing series of improvement.

\section{A combined framework for embedding C\&IT}

There are several similarities between the three approaches described above. All, for example, stress the relationship between tutor and student. Moreover, none of the additional criteria proposed seems to contradict those of the other frameworks. For this reason, it is proposed that these could be unified to provide a single, coherent and inclusive framework, intended for use by practitioners wanting to embed C\&IT into their courses. It would be structured to include the following steps:

- establish current course overview;

- clarify the course's aims and learning outcomes;

- establish the methods, work and activities ('learning scenarios') required to achieve the aims and outcomes;

- identify the organization and presentation of the activities, identifying the method best suited to building on existing knowledge and capabilities of the students, considering appropriateness of the learning media, and the flexibility of sequencing; 
- for each activity, consider whether to write, buy or adopt supporting materials;

- select appropriate assessment models;

- link the individual learning scenarios to form a unified course;

- identify student access needs and skill requirements;

- establish resource requirements, and infrastructure requirements (e.g. a need for staff training) where appropriate.

In addition to drawing together the three approaches outlined above, this framework adds two new elements. The first is the focus of analysis being shifted to 'learning scenarios', rather than courses. This term is intended to describe any educational interaction (e.g. a lecture, a discussion, a group project), and will be defined in more detail in the following section. Analysis at this level is argued to be more appropriate than analysis at a coursewide level, since resources relevant to one activity may not be well suited to another. Course-wide C\&IT use is then considered when the learning scenarios are reintegrated, when the focus is on unifying individual components. The second element which has been introduced is the analysis of course composition in terms of its aims and outcomes. A focus on embedding C\&IT often neglects the fact that existing courses may be less than ideal, and could be improved by altering the range of activities they involve.

\section{Definition and characteristics of a learning scenario}

In the previous section, it was proposed that the embedding C\&IT into the curriculum most effectively required an analysis of courses at the level of educational activities, which were referred to as 'learning scenarios'. This catch-all term has been introduced in order to avoid pre-conceived ideas of what constitutes learning and teaching, leaving these decisions to the practitioners using the framework.

Learning scenarios are defined to include several characteristics, including:

- media type;

- use of media;

- the preparatory work required;

- the educational interactions which are supported;

- the delivery constraints.

Media type is used in the sense proposed by Laurillard (1993). The use of media is simply a specification of the way in which the chosen media type is to be used. Consideration of these will determine the last three qualities: preparatory work required, educational interactions, and delivery constraints. One example of a learning scenario would be a lecture, drawing on the tutor's own notes, introducing algebra to a group of students. Another would be a group project by geographically remote students involving Web-based discussion and research, leading to a report on public attitudes to science. The concept of learning scenarios allows this diversity of educational activities to be referred to with one common term, and, more importantly, identifies a set of qualities which allow these activities to be compared. 
The remainder of this section explores the qualities of learning scenarios in greater depth.

\section{Media type and use}

The media types proposed by Laurillard (1993) form a useful and fairly comprehensive review of resources and activities that can be used to support the process of teaching and learning. For convenience, traditional teaching methods such as seminars, lectures and tutorials will also be referred to as 'media types', simply because they also provide support for educational interactions.

At least as important as the type of media adopted is the use it is put to. Using a simulation to teach laboratory skills is clearly a very different activity from using the same simulation as the starting point for a debate on software design, which has obvious implications for the educational interactions supported.

\section{Preparatory work}

The process of preparing for an educational interaction will vary between different learning scenarios. Some, such as student-led seminars, require comparatively little preparation on the part of the tutor; in contrast, a multimedia CD-ROM developed inhouse would require extensive preparation from a team of tutors and software developers. These issues have considerable impact in terms of the cost-effectiveness of C\&IT use, since pre-prepared materials will require far less staff time than developing new resources (Harrison, 1994).

To provide some comparison between the associated costs of adopting, revising and developing different types of media, a comparison table was piloted with focus-group software developers and educational technologists. The resulting comparisons between media, covering staff time and resources required to support the preparations, are gathered together in Table 1 . The table has been arranged with technology-based media preceding traditional forms of teaching.

It should be noted that the figures and resources are based on 'best-guesses' of experts, rather than surveys of staff use, and so should be seen as indicative rather than definitive. The table is intended to be used as a tool by practitioners transforming courses; it would be for them to estimate associated time and resource implications, using informed examples where necessary, in order to arrive at a comparison between the media types available to them.

\section{Educational interactions}

While the information given in Table 1 allows a comparison of media types in terms of the associated preparatory work and associated requirements, it fails to detail the range of educational interactions that can be supported. Instead, these have been modelled using Laurillard's conversational framework (Laurillard, 1993), shown in Figure 1.

This framework has already been used to identify the educational interactions which orthodox uses of teaching media support (Laurillard, 1993). The 12 educational interactions it describes have been used as the basis of an educational comparison between uses of media. However, it is suggested that the original system of classification, while useful, lacks the detail required for a pragmatic comparison of media types. Moreover, by concentrating on 'orthodox' uses, it neglects individual differences in practitioners' styles. For these reasons, the classification system has been altered from a Yes/No response to a 


\begin{tabular}{|c|c|c|c|c|}
\hline Media type & Examples of organizing the structure & $\begin{array}{l}\text { New } \\
\text { (hours) }\end{array}$ & $\begin{array}{l}\text { Existing } \\
\text { (hours) }\end{array}$ & Resources required \\
\hline Asynchronous bulletin board & Set up forums and write activities & $2-5$ & 0 & B8 Software \\
\hline Audio-vision & Prepare script and record, write handout & $50-200$ & $5-20$ & Recording equipment, seript \\
\hline Audio-cassette & Prepare script and record & $20-100$ & $2-10$ & Recording equipment, script \\
\hline Broadeast TV & Prepare script and record & $50-500$ & $5-20$ & Recording equipment, script \\
\hline Email & Define use & $0-1$ & 0 & Enail software \\
\hline Fill in the gaps & Design and word process fill in the gaps & $5-20$ & $1-5$ & - \\
\hline Hypertext & Produce HTML documents and gifs & $2-10$ & $5-20$ & HTML editor, browser \\
\hline Microworlds & $\begin{array}{l}\text { Author microworld or provide } \\
\text { accompanying explanations }\end{array}$ & $5-200$ & $5-20$ & $\begin{array}{l}\text { MMPC microworld software, } \\
\text { authoring software }\end{array}$ \\
\hline Multimedia & Author material and record clips & $100-200$ & $\begin{array}{l}5-20 \\
\text { audio) }\end{array}$ & $\begin{array}{l}\text { MMPC, Multimedia software } \\
\text { (authoring, graphics, and }\end{array}$ \\
\hline Radio & Prepare script and record & $20-100$ & $2-10^{\circ}$ & Broadcasting equipment, script \\
\hline SAQS & Author questions & $5-20$ & $2-5$ & Assessment software \\
\hline Simulations & $\begin{array}{l}\text { Author simulation or set the scene for } \\
\text { the exercise }\end{array}$ & $5-100$ & $5-20$ & $\begin{array}{l}\text { MMPC, simulation software, } \\
\text { authoring software }\end{array}$ \\
\hline $\begin{array}{l}\text { Synchronous audio } \\
\text { conferencing }\end{array}$ & Set the scene & $2-3$ & 0 & $\begin{array}{l}\text { Broadcasting and reception } \\
\text { equipment and/or software }\end{array}$ \\
\hline Symchronous chat systems & Write instructions and define use & $0-1$ & 0 & Chat software \\
\hline $\begin{array}{l}\text { Synchronous. video } \\
\text { conferencing }\end{array}$ & Set the scene or prepare "lecture" & $2-5$ & 0 & $\begin{array}{l}\text { Broadcasting and reception } \\
\text { equipment and/or software }\end{array}$ \\
\hline Tutorial Program & Author program or provide instructions & $20-100$ & $5-20$ & $\begin{array}{l}\text { MMPC, tutoring software, } \\
\text { authoring software }\end{array}$ \\
\hline Tutorial Simulation & Author program or provide instructions & $75-300$ & $5-20$ & $\begin{array}{l}\text { MMPC, tutoring software, } \\
\text { authoring software }\end{array}$ \\
\hline Tutorial System & Author program or provide instructions & $50-200$ & $5-20$ & $\begin{array}{l}\text { MMPC, tutoring software, } \\
\text { authoring software }\end{array}$ \\
\hline Video-cassette & Prepare script and record & $50-200$ & $5-20$ & Recording equipment, script \\
\hline Whiteboards & Prepare instructions for use & $1-2$ & 0 & Whiteboard software \\
\hline Fieldtrips & Prepare activities, arrange bookings & $5-20$ & 0 & $\begin{array}{l}\text { Transport location, } \\
\text { accommodation }\end{array}$ \\
\hline Formal exam & Word Process, Exam boards & $10-15$ & 0 & - \\
\hline Lecture & $\begin{array}{l}\text { Organize notes write OHPs or } \\
\text { slide presentations }\end{array}$ & $2-5$ & 0 & $\begin{array}{l}\text { Overheads, presentation } \\
\text { software }\end{array}$ \\
\hline Practicals & $\begin{array}{l}\text { Design and test experiments } \\
\text { Write manual, Order materials }\end{array}$ & $10-20$ & 0 & Lab, equipment, materials \\
\hline Print (handouts or workbooks) & Word process material & $5-20$ & $1-5$ & - \\
\hline Progress tests & Wond process & $2-5$ & 0 & - \\
\hline Seminar & Set seminar topic & $0-3$ & 0 & - \\
\hline Tutorial - S/S & Setting the scene for student-led tutorial & $0-1$ & 0 & - \\
\hline Tutorial -T/S & Prepare tutorial sheet & $2-5$ & 0 & - \\
\hline
\end{tabular}

Table 1: Preparatory work comparison chart

grading. This grading rates media uses from 0 (rarely if ever supports this interaction) to 3 (this interaction is central). This provides a much finer analysis of the strengths and weaknesses of resources, providing a clearer picture of the educational benefits of different media uses.

As with the preparation work table (Table 1), it is proposed that this be worked through by practitioners involved in embedding C\&IT. This ensures that the system accurately reflects individuals' teaching styles, and avoids being prescriptive. The results shown in the tables 


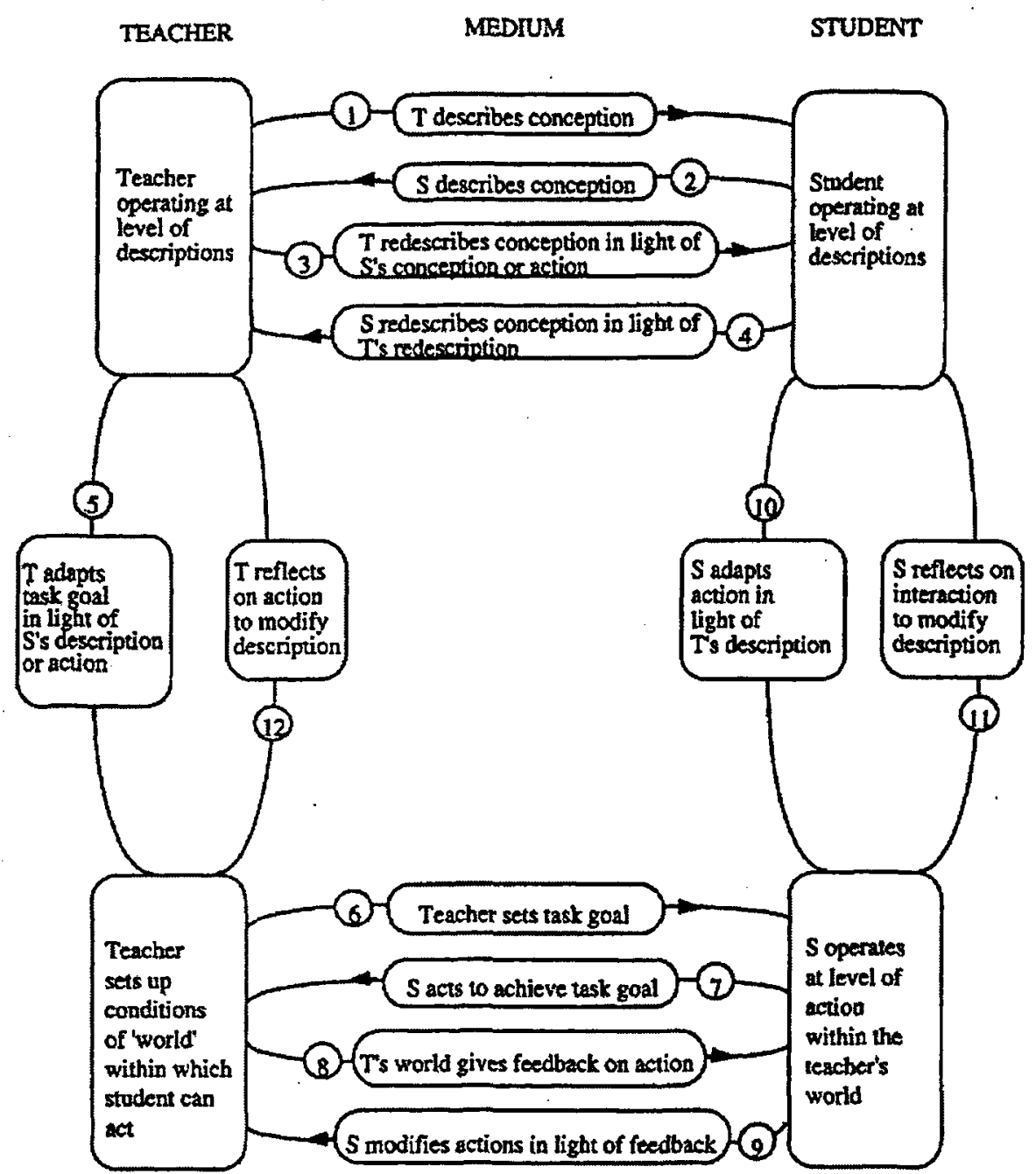

Figure 1: Laurillard's conversational framework

have been collated from tables completed by the same five subjects who completed Table 1 , and are again intended to be illustrative rather than definitive. In the tables, the numbers 1 to 3 are replaced by asterisks.

Table 2 presents the interactions for traditional learning situations, such as lectures and tutorials, and Table 3 repeats this process for computer-based media. Worth noting are the low scores assigned to tutor reflection on many of the computer-based media. This reflects a worry that tutors who rely on these in place of face-to-face teaching may lose track of students' progress.

The scores also stress the value of traditional teaching using tutorials and seminars. This complements research which shows what students enjoy most is small group tutorials, and 


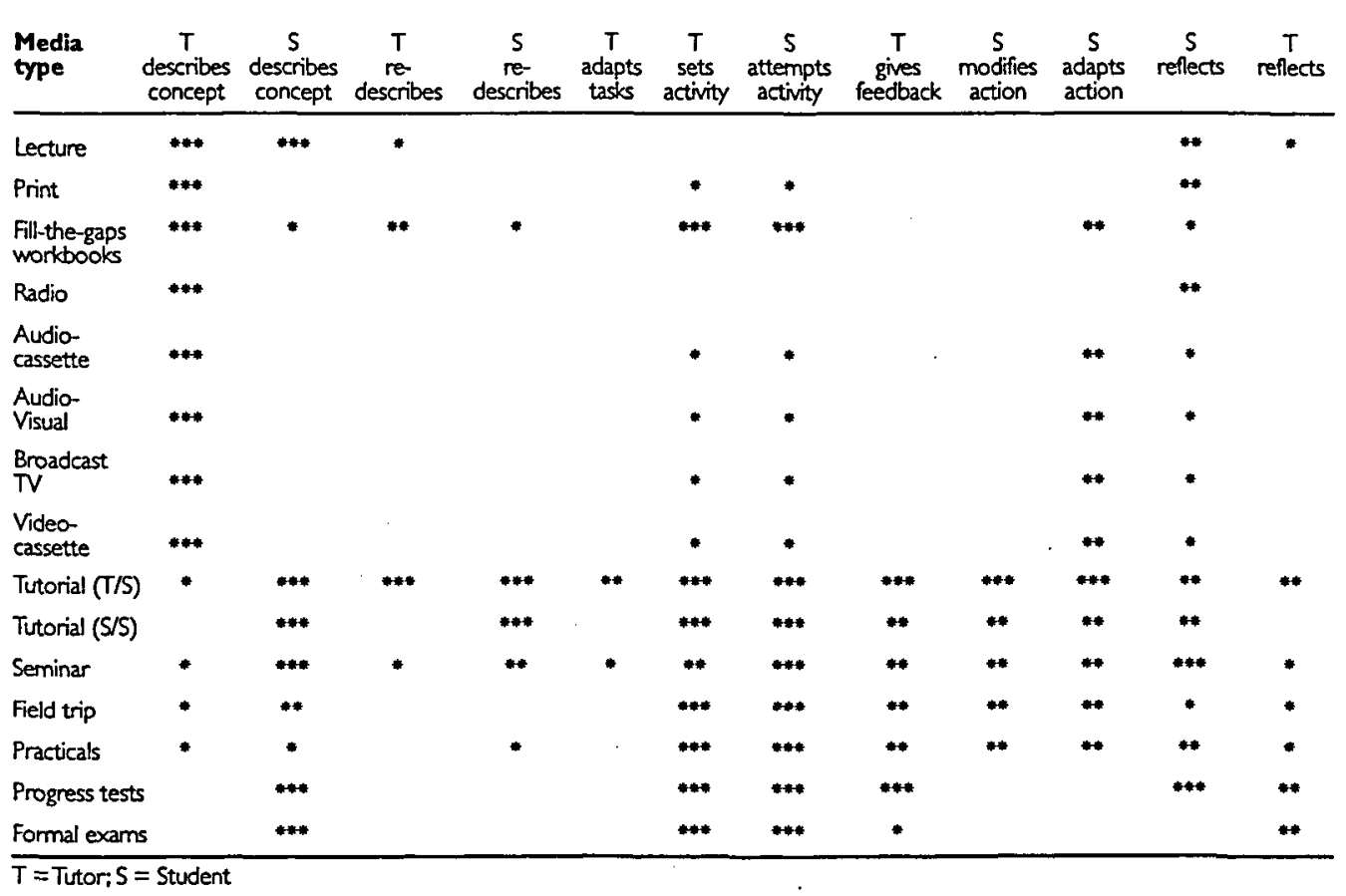

Table 2: A comparison of traditional teaching media in terms of educational interactions

\begin{tabular}{|c|c|c|c|c|c|c|c|c|c|c|c|c|}
\hline $\begin{array}{l}\text { Media } \\
\text { type }\end{array}$ & $\begin{array}{c} \\
\text { describes } \\
\text { concept }\end{array}$ & $\begin{array}{c}\mathrm{S} \\
\text { describes } \\
\text { concept }\end{array}$ & $\begin{array}{c}\mathrm{T} \\
\mathrm{re} \\
\text { describes } \\
\end{array}$ & $\begin{array}{c}\text { S } \\
\text { re- } \\
\text { describes }\end{array}$ & $\begin{array}{c}\mathrm{T} \\
\text { adapts } \\
\text { tasks }\end{array}$ & $\begin{array}{c}\mathrm{T} \\
\text { sets } \\
\text { activity }\end{array}$ & $\begin{array}{c} \\
\text { attempts } \\
\text { activity }\end{array}$ & $\begin{array}{c}\mathbf{T} \\
\text { gives } \\
\text { feedback }\end{array}$ & $\begin{array}{c}S \\
\text { modifies } \\
\text { action }\end{array}$ & $\begin{array}{c}S \\
\text { adapts } \\
\text { action }\end{array}$ & $\begin{array}{c}5 \\
\text { reflects }\end{array}$ & $\stackrel{T^{\top}}{\text { reflects }}$ \\
\hline Hypertext & $* * *$ & & $*$ & & $*$ & $*$ & $* *$ & * & * & $*$ & $*$ & \\
\hline Multimedia & $* *$ & & - & & * & $* *$ & $* *$ & $*$ & $*$ & $*$ & $* *$ & \\
\hline$C A L$ & $* * *$ & * & * & $*$ & & $* *$ & $* * *$ & * & * & - & * & \\
\hline $\begin{array}{l}\text { Tutoring } \\
\text { systems }\end{array}$ & $* * m$ & $* *$ & $*$ & $* *$ & $* *$ & $* *$ & $* * *$ & $* * *$ & $* * *$ & $*$ & $*$ & \\
\hline $\begin{array}{l}\text { Tutorial } \\
\text { simulations }\end{array}$ & $* *$ & - & • & & $*$ & * & $* *$ & $*$ & $*$ & $* *$ & $*$ & \\
\hline Simulations & $* * *$ & & & & & $*$ & • & & & $*$ & $* *$ & \\
\hline Microworlds & & $* *$ & & & & $*$ & $* *$ & & * & $* *$ & ** & \\
\hline Email & * & $*$ & $* *$ & $* *$ & ** & $*$ & * & $*$ & * & * & $* *$ & $*$ \\
\hline Chat system & $*$ & *a* & - & $*$ & $*$ & • & $* *$ & $* * *$ & $*$ & $*$ & $* *$ & $*$ \\
\hline $\begin{array}{l}\text { Asynchronous } \\
\text { bulletin board }\end{array}$ & s. & $* * *$ & $*$ & $* *$ & $*$ & $* *$ & ** & $* * *$ & $*$ & $*$ & $* *$ & $*$ \\
\hline $\begin{array}{l}\text { Sync. audio } \\
\text { conference }\end{array}$ & * & **** & $* *$ & $* * *$ & - & $* * *$ & $* * *$ & $* *$ & $*$ & $*$ & $*$ & 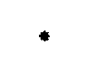 \\
\hline $\begin{array}{l}\text { Sync. video } \\
\text { conference }\end{array}$ & $*$ & $* * *$ & $* *$ & $* * *$ & $*$ & $* * *$ & $* *$ & $* *$ & ** & $*$ & "* & " \\
\hline Whiteboard & & $*$ & $*$ & $*$ & * & & $*$ & $* *$ & $* *$ & $* *$ & & $*$ \\
\hline SAQS & & $* * *$ & & & $\cdot$ & $*$ & $* *$ & $* *$ & $*$ & & $* *$ & \\
\hline
\end{tabular}

$T=$ Tutor, $S=$ Student

Table 3: A comparison of computer-based teaching media in terms of educational interactions 
can happily do without lectures (Harrison, 1994). A balance between uses of computerbased and traditional media can also help shift the emphasis of contact time with tutor and staff. Resources such as CAL or hypertext could be used in place of lectures, where the emphasis is on exposition of information, freeing staff time for discussion-based meetings of small groups (cf. Lewis and Merton, 1996). Use of appropriate technologies, for example videoconferencing or synchronous conferencing systems, would allow these benefits to be extended to distance learners (Harrison, 1994).

That the results shown in Tables 2 and 3 have highlighted both the issue and a potential solution suggests that requiring practitioners to work through these as part of the process of embedding C\&IT is a useful and practical exercise.

\section{Delivery constraints}

The final characteristic of learning scenarios is the set of delivery constraints with which they are associated. These include restrictions on time and location for the delivery and accessing of information, and may involve specific hardware, software, personnel or environmental requirements. These will often dictate the spaces and facilities required to support the learning scenario. These constraints are presented for traditional and computer-based media in Tables 4 and 5 . As with the other tables in this report, this information is intended to be illustrative rather than prescriptive.

The codes used in the student location column indicate different types of venue. Five abbreviations are used:

Open Access Machines (OAM), for individual access, housed in computer rooms.

Library Centre (LC), providing open access machines and areas for individual study.

Group Work Computers (GWC), housed in a room designated for use by classes or large groups of students, and supporting face-to-face discussion as well as on-line communication.

\section{Lecture Room (LR).}

Seminar Room (SR).

These five types of provision should cover the majority of modes of delivery used by universities.

\section{Linking learning scenarios to form integrated courses}

Having defined and explored the qualities of learning scenarios, what remains is to link the individual activities to form an integrated course. This involves sequencing and linking the scenarios, and integrating these with the role of the teacher (Harrison, 1994). Additionally, a coherent front-end needs to be provided for students, and integrated support for course administration needs to be supported. These will ensure the smooth dissemination of information and course-related announcements between the faculty and students.

A number of media types can be used to support these requirements, including paperbased post, Web-based timetables, email distribution lists, and so on. Whichever media type is chosen, it should be able to support as many of the required functions as possible. Requiring students to access a variety of media in order to find the information they require will present a far less cohesive appearance to the course. 


\begin{tabular}{|c|c|c|c|c|c|c|c|c|}
\hline \multirow[t]{2}{*}{ Media type } & \multicolumn{2}{|c|}{$\begin{array}{c}\text { Time } \\
\text { dependent }\end{array}$} & \multicolumn{2}{|c|}{$\begin{array}{l}\text { Location } \\
\text { dependent }\end{array}$} & \multirow{2}{*}{$\begin{array}{c}\text { Usually } \\
\text { involves a } \\
\text { co-present } \\
\text { group }\end{array}$} & \multirow{2}{*}{$\begin{array}{c}\text { Usually } \\
\text { involves } \\
\text { group } \\
\text { work }\end{array}$} & \multirow[t]{2}{*}{ Requirements } & \multirow[t]{2}{*}{$\begin{array}{l}\text { Location } \\
\text { of student }\end{array}$} \\
\hline & Tutor & Student & Tutor & Student & & & & \\
\hline Lecture & $\checkmark$ & $\checkmark$ & $\checkmark$ & $\checkmark$ & $\checkmark$ & $x$ & $\begin{array}{l}\text { Presentation equipment } \\
\text { (e.g. OHP, whiteboard, } \\
\text { PowerPoint etc.) }\end{array}$ & $L R$ \\
\hline Print & $x$ & $x$ & $x$ & $x$ & $x$ & $x$ & Book/handout & LC \\
\hline $\begin{array}{l}\text { Fill-the-gaps } \\
\text { workbooks }\end{array}$ & $x$ & $x$ & $x$ & $x$ & $x$ & $x$ & Workbook & LC \\
\hline Radio & $\checkmark$ & $\checkmark$ & $x$ & $x$ & $x$ & $x$ & Broadcast \& reception equipment & nt $L C$ \\
\hline Audio-Cassette & $x$ & $x$ & $x$ & $x$ & $x$ & $x$ & Cassette player & LC \\
\hline Audio-Visual & $x$ & $x$ & $x$ & $x$ & $x$ & $x$ & Cassette player \& workbook & LC \\
\hline Broadcast TV & $x$ & $\checkmark$ & $x$ & $x$ & $x$ & $x$ & Broadcast \& reception equipment & nt $L C$ \\
\hline Video Cassette & $x$ & $x$ & $x$ & $x$ & $x$ & $x$ & Recording \& viewing equipment & LC \\
\hline Tutorial (T/S) & $\checkmark$ & $\checkmark$ & $\checkmark$ & $\checkmark$ & $\checkmark$ & $\checkmark$ & Room tutorial staff & $S R$ \\
\hline Tutorial (S/S) & $x$ & $\checkmark$ & $x$ & $\checkmark$ & $\checkmark$ & $\checkmark$ & Room & SR \\
\hline Seminar & $\checkmark$ & $\checkmark$ & $\checkmark$ & $\checkmark$ & $\checkmark$ & $\checkmark$ & Room & SR \\
\hline Field trip & $\checkmark$ & $\checkmark$ & $\checkmark$ & $\checkmark$ & $\checkmark$ & Sometimes & Location, accommodation & External \\
\hline Practicals & $\checkmark$ & $\checkmark$ & $\checkmark$ & $\checkmark$ & $\checkmark$ & Sometimes & Lab. manual, technician staff & Lab \\
\hline Progress tests & $\checkmark$ & $\checkmark$ & $\checkmark$ & $\checkmark$ & $\checkmark$ & $x$ & Room, test & $S R$ or $L R$ \\
\hline Formal exams & $\checkmark$ & $\checkmark$ & $\checkmark$ & $\checkmark$ & $\checkmark$ & $x$ & Room, exam & Hall \\
\hline
\end{tabular}

Table 4: Delivery constraints comparison chart troditional media

This unification of administrative support also provides opportunities to build a sense of a learning community amongst the students, enhancing the atmosphere of the course. Other possible benefits of computer-based support automated profiling, which will help address the potential problems of staff losing touch with students as a result of reduced staff/student contact time.

\section{A methodology for enhancing course delivery}

In the previous section, a way of analysing courses in terms of the learning scenarios they consist of was presented. This analysis can be used as the basis for a methodology which allows courses to be enhanced through the embedding of C\&IT resources in a pedagogically sound way.

This methodology involves a step-by-step analysis of requirements, starting from existing courses, leading to the identification of computer-based resources capable of enhancing learning, a specification of the type of venues capable of supporting this kind of learning, and a procedure for linking these scenarios together to form a new, cohesive and unified course. Central to this process is the tutor's knowledge and understanding of the course (Harrison, 1994). For this reason, the methodology is intended to be used by practitioners, allowing them to identify and compare alternatives to the learning scenarios currently in use.

This methodology involves the following stages:

- A review of current course structure, identifying the existing learning situations.

- An examination of the current course structure to establish areas of learning which could be enhanced. 
Grainne Conole and Martin Oliver A pedagogical framework for embedding C\&IT into the curriculum

\begin{tabular}{lcccccccc}
\hline Media type & $\begin{array}{c}\text { Time } \\
\text { dependent }\end{array}$ & \multicolumn{1}{c}{$\begin{array}{c}\text { Location } \\
\text { dependent }\end{array}$} & $\begin{array}{c}\text { Usually } \\
\text { involves a } \\
\text { co-present } \\
\text { group }\end{array}$ & $\begin{array}{c}\text { Usually } \\
\text { involves } \\
\text { group } \\
\text { work }\end{array}$ & Requirements & Location \\
of student
\end{tabular}

Table 5: Delivery constraints comparison chart: computer-based media

- Working through the media comparison tables to establish possible replacements or additions to the learning situations in the course. Course tutors should fill out these tables as part of the transformation process, providing a better understanding of the media involved, and ensuring that the weightings in the table accurately reflect their style of teaching.

- A comparison between the original and enhanced learning situations to establish which should be adopted, to cover:

- Development/preparatory work requirements, aiming to minimize these.

- The educational interactions each supports, aiming to maximize these.

- The delivery constraints, specifying the time and location requirements of each option, aiming to make these as flexible as possible.

- Linking the learning scenarios to provide an integrated course.

This five-stage process provides a supportive method of transforming and enhancing courses. Rather than being prescriptive, it seeks to highlight issues for the tutor to consider, and provide tools which can be used to address them. An example of the application of this methodology to a course can be found in Conole and Oliver (1997).

\section{Conclusions}

This paper has outlined a methodology for embedding C\&IT into courses in a pedagogically sound way. The methodology extends approaches currently put forward for embedding C\&IT by providing a framework of issues which will influence the choice of resource and the way in which it is used. This is based on an analysis of courses in terms of 
the learning scenarios they consist of. An example of how this process can be applied is presented to illustrate this process.

Whilst this report has focused on integrating C\&IT at a course level, there are a range of potential barriers to this process which can arise within institutions. Embedding C\&IT requires institutional and departmental commitment to make innovation the norm, rather than an exception (Maier $e t$ al, 1997). To achieve this, it is likely that University-wide staff development will be needed. It is vital that staff be aware of and trained with new technologies if they are used effectively. Training in the use of the methodology outlined in this report could be complemented by a broad programme of training with a variety of C\&IT resources.

Whilst this pedagogical framework is intended primarily as a focus for discussion, both in terms of staff involved in course transformation and research into this area, its timeliness in the light of the Dearing report and initiatives such as phase three of the TLT project simply enhances its importance as a way of guiding the use of C\&IT .

\section{Acknowledgements}

We would like to thank the following people at the University of North London for their helpful comments on this paper: Ray Jones, Jan McEneany and David Riley. The funding of BP Chemicals Ltd. of the Evaluation of Learning Technologies project is also acknowledged.

\section{References}

Conole, G. and Oliver, M. (1997), A Pedagogic Framework for Embedding C\&IT into the Curriculum, BP ELT Report no. 2, University of North London.

Ford, P., Goodyear, P., Heseltine, R., Lewis, R., Darby, J., Graves, J., Satorius, P., Harwood, D. and King, T. (1996), Managing Change in Higher Education: A Learning Environment Architecture, Buckingham: Open University Press.

Harrison, C. (1994), 'The role of learning technology in planning change in curriculum delivery and design', $A L T-J, 2$ (1), 30-7.

Laurillard, D. (1993), Rethinking University Teaching, London: Routledge.

Dearing, R. et al (1997), Higher Education in the Learning Society, Report of the National Committee of Inquiry into Higher Education. London: NCIHE Publications (HMSO), July.

Laurillard, D., Swift, B. and Darby, J. (1993), 'Academics' use of courseware materials: a survey', $A L T-J 1$ (1), 4-14.

HEFCE (1997a), Information Technology Assisted Teaching and Learning in Higher Education (ITATL report), Bristol: HEFCE Research series.

HEFCE (1997b), Teaching and Learning Technology Programme Phase 3: Invitation to Bid, Circular 14/97, Bristol: TLTP.

Clark, P. (1997), 'Response to the Report: recommendations of the National Committee' in 
Beetham, H. (ed.), IT and Dearing: The Implications for HE Colloquium Proceedings, London: CTI, 6-16.

Maier, P., White, S. and Barnett, L. (1997), 'Using educational development strategies to integrate learning technologies', Active Learning, 6, 10-14.

Mapp, L. (1994), 'Learning from learning technology: a framework of implementation issues, The CTISS File, 17, 23-6.

Lewis, R. and Merton, B. (1996), Technology for Learning: Where are We Going?, Independent Learning Unit position paper, University of Lincoln and Humberside.

McAleese, R., Collis, B., Jacobs, G., Somekh, B. and King, T. (1997), 'A review of Managing Change in Higher Education: A Learning Environment Architecture', ALT-J, 5 (2), 64-74.

Grabinger, S., Dunlap, J. and Duffield, J. (1997), 'Rich Environments for Active Learning in action: problem-based learning', ALT-J, (5) 2, 5-17. 